\title{
The effect of intravenous glucose solutions on neonatal blood glucose levels after cesarean delivery
}

\author{
Isao Fukuda · Hideo Matsuda • Shinya Sugahara • \\ Tomiei Kazama
}

Received: 23 February 2012/ Accepted: 28 October 2012/Published online: 11 November 2012

(C) The Author(s) 2012. This article is published with open access at Springerlink.com

\begin{abstract}
Purpose Intravenous solutions are often administered to the mother on the day of a cesarean delivery to minimize the effect of preoperative fasting or to stabilize the hemodynamics. Different intravenous solutions contain varying amounts of glucose, and rapid administration may lead to hypoglycemia in the neonate. We conducted a study to compare blood glucose levels of the mother and the fetus/neonate after they were rapidly given a Ringer's solution containing 0,1 , or $5 \%$ glucose. The effect of the glucose load that these intravenous solutions impose during cesarean delivery has not been fully reported. Therefore, we compared the effect of $0 \%$ (Group I, $n=15$ ), $1 \%$ (Group II, $n=15$ ), and $5 \%$ (Group III, $n=15$ ) glucose acetated Ringer's solutions on maternal and umbilical blood glucose levels to determine the optimal glucose concentration.

Methods Once the patients were in the operating room, the intravenous solutions were administered before delivery. The primary endpoint was changes in umbilical blood glucose levels and minimum neonatal blood glucose levels, and the secondary endpoint was the proportion of neonates who received a glucose infusion.
\end{abstract}

I. Fukuda $(\bowtie) \cdot$ S. Sugahara

Department of Anesthesiology, National Hospital Organization

Tokyo National Hospital, 3-1-1 Takeoka, Kiyose,

Tokyo 204-8585, Japan

e-mail: a6m3_hamp@me.com

H. Matsuda

Department of Obstetrics and Gynecology, Matsuda Perinatal Clinic, Saitama, Japan

T. Kazama

Department of Anesthesiology, National Defense Medical

College, Saitama, Japan
Results Maternal blood glucose levels before and after intravenous infusion were $79.2 \pm 12.2$ and $74.6 \pm 4.6$ in Group I, $81.2 \pm 12.9$ and $103.3 \pm 11.2$ in Group II $(P<0.001)$, and $82.3 \pm 8.7$ and $252.5 \pm 41.8$ in Group III $(P<0.001)$. Umbilical blood glucose levels were $53.9 \pm$ 10.2 in Group I, $80.8 \pm 13.7$ in Group II, and $181.8 \pm 22.2$ in Group III $(P<0.01$ : Group I vs. Group II and $P<0.01$ : Group II vs. Group III) $(P<0.001$ : Group I vs. Group III). Minimum neonatal blood glucose levels measured up to $8 \mathrm{~h}$ after birth were $35.7 \pm 9.6$ in Group I, $49.8 \pm 10.8$ in Group II, and $29.2 \pm 7.5$ in Group III. Neonatal hypoglycemia requiring glucose before the first milk feeding occurred in 6 neonates whose mothers were in Group I, 3 in Group II, and 9 in Group III, indicating a trend towards less neonatal hypoglycemia in Group II.

Conclusions The use of $1 \%$ glucose acetated Ringer's solution did not induce hyperglycemia in the mother and it was able to maintain appropriate blood glucose levels in the fetus.

Keywords $1 \%$ glucose acetated Ringer's solution . Blood glucose $\cdot$ Perioperative infusion

\section{Introduction}

Intravenous glucose solutions may be given to patients who undergo cesarean deliveries to provide the mother and fetus with energy, and glucose-free crystalloid solutions are given to maintain hemodynamics. However, glucose load from preoperative intravenous solutions may result in hyperglycemia or hypoglycemia in the fetus.

Anesthesia induction often causes an abrupt change in hemodynamics, and such change, especially a decrease in blood pressure, harms both mother and fetus. To reverse the 
Table 1 Composition of test solutions

\begin{tabular}{|c|c|c|c|c|c|c|c|c|c|c|c|}
\hline Name & $\begin{array}{l}\text { Group } \\
\text { name }\end{array}$ & $(\mathrm{mEc}$ & $\mathrm{K}^{+}$ & $\mathrm{Ca}^{+}$ & $\mathrm{Mg}^{+}$ & $\mathrm{Cl}^{-}$ & Gluconate $^{-}$ & Citrate $^{3-}$ & Acetate $^{-}$ & $\begin{array}{l}\text { Glucose } \\
(\%)\end{array}$ & $\begin{array}{l}\text { Osmotic } \\
\text { pressure } \\
\text { ratio }\end{array}$ \\
\hline $\begin{array}{l}0 \% \text { Glucose acetated } \\
\text { Ringer's solution }\end{array}$ & Group I & 130 & 4 & 3 & - & 109 & - & - & 28 & - & Approx. 1 \\
\hline $\begin{array}{l}1 \% \text { Glucose acetated } \\
\text { Ringer's solution }\end{array}$ & Group II & 140 & 4 & 3 & 2 & 115 & 3 & 6 & 25 & 1 & Approx. 1 \\
\hline $\begin{array}{l}5 \% \text { Glucose acetated } \\
\text { Ringer's solution }\end{array}$ & Group III & 130 & 4 & 3 & - & 109 & - & - & 28 & 5 & Approx. 2 \\
\hline
\end{tabular}

change, a vasopressor is promptly administered, and rapid intravenous infusion is often performed to have a faster effect. However, depending upon the intravenous solutions used, rapid administration may result in maternal and fetal hyperglycemia, which eventually could lead to reflex hypoglycemia in the neonate [1]. The optimal glucose concentration for intravenous solutions that would be effective for maintaining a safe range of blood glucose both in mothers and fetuses has not been established. Normally, mothers with blood glucose levels of $40 \mathrm{mg} / \mathrm{dL}$ or lower and fetuses with levels of $30 \mathrm{mg} / \mathrm{dL}$ or lower are diagnosed as having hypoglycemia [2]. A neurophysiological study indicates that developmental disorders will occur if the neonate's blood glucose level becomes $2.6 \mathrm{mmol} / \mathrm{L}$ (equivalent to $48 \mathrm{mg} / \mathrm{dL}$ ) or lower, which is consistent with the diagnostic criterion previously mentioned [3]. Intravenous solutions of acetated Ringer's used during surgery can be generally categorized based on glucose load into the following 3 types: $0 \%$ acetated Ringer's solution (no glucose, $500 \mathrm{~mL}), 1 \%$ acetated Ringer's solution $(5 \mathrm{~g}$ glucose, $500 \mathrm{~mL})$, and $5 \%$ acetated Ringer's solution $(25 \mathrm{~g}$ glucose, $500 \mathrm{~mL}$ ) (Table 1). The effect of the glucose load that these intravenous solutions impose during cesarean delivery has not been fully reported. Therefore, we compared the effect of 0,1 , and $5 \%$ glucose acetated Ringer's solutions on maternal and umbilical blood glucose levels to determine the optimal glucose concentration.

\section{Patients and methods}

The study was approved by the Institutional Ethics Committee of the National Defense Medical College. The patients were fully informed about the study, and written informed consent was obtained. Forty-five pregnant women scheduled for elective cesarean delivery were included. Patients with gestational diabetes or pregestational diabetes or those receiving intravenous solutions with glucose due to preoperative complications, such as threatened premature labor, were excluded.

The 45 patients were randomly assigned to 3 groups: $0 \%$ glucose acetated Ringer's solution (Group I), $1 \%$ glucose acetated Ringer's solution (Group II), and $5 \%$ glucose acetated Ringer's solution (Group III). All patients received an infusion of $0 \%$ glucose acetated Ringer's solution $(1000-1500 \mathrm{~mL})$ via the forearm the day before their surgery was scheduled; preoperative fasting started at 21:00 the night before the scheduled cesarean delivery section. Patients were not given any other medications, including anesthetics, before their scheduled delivery (Fig. 1).

Lumbar epidural anesthesia was performed by injecting $15 \mathrm{~mL}$ of $1 \%$ ropivacaine via the L3-4 interspace. A Teflon needle was placed in the radial artery to monitor arterial pressure and to take maternal blood samples. Each group received $500 \mathrm{~mL}$ of the test solution, and administration was completed before delivery. As for glucose load; Group I received $0 \mathrm{~g}$ glucose; Group II, $5 \mathrm{~g}$ glucose; and Group III, $25 \mathrm{~g}$. To determine glucose levels, maternal blood samples were obtained before intravenous infusion and immediately after delivery; umbilical blood was obtained immediately after delivery to measure glucose levels and $\mathrm{pH}$. The neonate's body weight was also measured and the Apgar score determined by a neonatologist. Neonates with a minimum blood glucose level of $50 \mathrm{mg} / \mathrm{dL}$ or lower within $8 \mathrm{~h}$ of delivery were given a glucose infusion.

Results were expressed as mean $\pm \mathrm{SD}$ and median (minimum-maximum). One-way analysis of variance (two-sided at $\alpha=0.05$ ) and Chi-squared test were performed for statistical analyses by using Prism 5 for Mac OS X (1992-2008, GraphPad Software, Inc.). If one-way ANOVA gave a $P$ value less than 0.05 , a post hoc test (Dunnett' method) was performed. Differences in the patient's demographic characteristics were considered significant at the 0.15 level.

\section{Results}

Cesarean deliveries were performed in patients with breech presentation $(22.2 \%)$, repeated cesarean section (CS) $(40.0 \%)$, maternal request $(0.04 \%)$, and after myomectory CS $(33.3 \%)$. 
Fig. 1 Time schedule of the study
Day before surgery

Day of sugery

\section{Mothers}

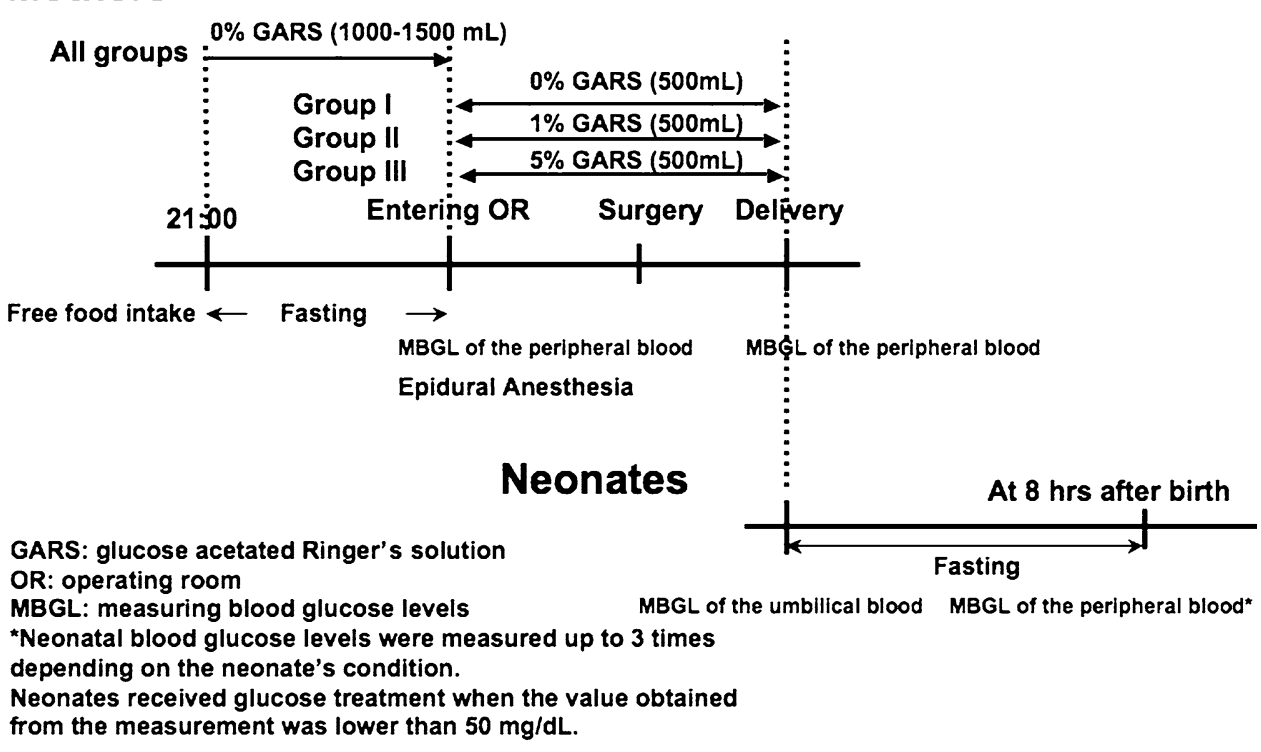

For the mothers, there were statistically significant differences in age, gestational week, and anesthesia time; whereas there were no differences in height, body weight, or amount of bleeding or oxytocin received (Table 2). For the neonates, there were no differences in body weight or Apgar scores (Table 3). Before and after the start of the intravenous infusion, the maternal blood glucose levels $(\mathrm{mg} / \mathrm{dL})$ were $79.2 \pm 12.2$ and $74.6 \pm 4.6$ in Group I, $81.2 \pm 12.9$ and $103.3 \pm 11.2$ in Group II, and $82.3 \pm 8.7$ and $252.5 \pm 41.8$ in Group III (Table 4). Group II and Group III showed significant differences in blood glucose levels before and after the start of the intravenous infusion (Group II, $P<0.001$; Group III, $P<0.001$ ), and betweengroup differences were noted; significant differences between the 3 groups were also found (Group I vs. Group II, $P<0.001$; Group II vs. Group III, $P<0.001$; Group I vs. Group III, $P<0.001$; one-way ANOVA, $P<0.05)$. Immediately after delivery, umbilical blood glucose levels $(\mathrm{mg} / \mathrm{dL})$ were $53.9 \pm 10.2$ in Group I, $80.8 \pm 13.7$ in Group II, and 181.8 \pm 22.2 in Group III (Table 5). Of the 3 groups, Group III had the highest blood glucose levels, and there were significant differences between the 3 groups (Group I vs. Group II, $P<0.01$; Group II vs. Group III, $P<0.01$; Group I vs. Group III, $P<0.001$; one-way ANOVA, $P<0.05)$. The minimum neonatal blood glucose levels within $8 \mathrm{~h}$ after birth $(\mathrm{mg} / \mathrm{dL})$ were $35.7 \pm 9.6$ in Group I, $49.8 \pm 10.8$ in Group II, and $29.2 \pm 7.5$ in Group III (Table 5). Group I and Group III showed significantly lower minimum blood glucose levels within $8 \mathrm{~h}$ after birth than in Group II (Group I vs. Group II, $P<0.05$; Group II vs. Group III, $P<0.01)$.
Based on the reference range of our institution, a neonate with a minimum blood glucose level of $50 \mathrm{mg} / \mathrm{dL}$ $(2.8 \mathrm{mmol} / \mathrm{L})$ or lower measured within $8 \mathrm{~h}$ after birth was diagnosed as having neonatal hypoglycemia and given treatment with a glucose infusion. In this study, 6 neonates in Group I, 3 in Group II, and 9 in Group III received a glucose infusion before the first milk feeding; neonates in Group II showed a trend towards a less frequent glucose infusion $(P=0.082)$ (Table 6).

\section{Discussion}

In our study, we compared maternal, umbilical, and neonatal ( $8 \mathrm{~h}$ after birth) blood glucose levels to investigate the optimal glucose infusion in neonates. Baseline maternal characteristics showed statistically significant differences in age, gestational week, and anesthesia time in 3 groups; however, they were not considered clinically important. As a result, those who received $1 \%$ glucose (Group II) had significantly lower glucose levels than other groups. There were significant differences in umbilical blood glucose and minimum neonatal blood glucose levels within $8 \mathrm{~h}$ after birth between groups receiving Ringer's solutions with different glucose concentrations $(0,1$, and $5 \%)$.

Generally, cesarean deliveries are performed under local anesthesia such as epidural or spinal anesthesia. However, local anesthesia often results in a decrease in blood pressure because of sympathetic nervous blockade, which should be promptly reversed because such hypotension will harm not only the mother but also the fetus. To stabilize the blood 
Table 2 Baseline maternal characteristics

\begin{tabular}{|c|c|c|c|c|}
\hline & $\begin{array}{l}0 \% \text { Glucose acetated Ringer's } \\
\text { solution Group I }(n=15)\end{array}$ & $\begin{array}{l}1 \% \text { Glucose acetated Ringer's } \\
\text { solution Group II }(n=15)\end{array}$ & $\begin{array}{l}5 \% \text { Glucose acetated Ringer's } \\
\text { solution Group III }(n=15)\end{array}$ & $P$ \\
\hline Age (year) & $34.5 \pm 2.6$ & $33.5 \pm 3.6$ & $31.9 \pm 4.1$ & 0.14 \\
\hline Height $(\mathrm{cm})$ & $158.4 \pm 4.2$ & $158.0 \pm 4.9$ & $157.0 \pm 6.3$ & 0.75 \\
\hline Body weight (kg) & $62.6 \pm 6.6$ & $61.7 \pm 6.5$ & $61.1 \pm 6.0$ & 0.79 \\
\hline Gestational week & $36.9 \pm 1.7$ & $37.4 \pm 2.7$ & $36.1 \pm 1.7$ & 0.13 \\
\hline $\begin{array}{l}\text { Amount of } \\
\text { oxytocin used (U) }\end{array}$ & $23.3 \pm 6.7$ & $22.7 \pm 14.5$ & $21.0 \pm 6.7$ & 0.80 \\
\hline Blood loss (g) & $1110 \pm 457.4$ & $912.7 \pm 354.7$ & $895.7 \pm 378.9$ & 0.84 \\
\hline $\begin{array}{l}\text { Anesthetic time } \\
(\min )\end{array}$ & $117.6 \pm 35.2$ & $115.3 \pm 41.6$ & $111.1 \pm 40.8$ & 0.07 \\
\hline
\end{tabular}

Mean \pm SD

One-way ANOVA, $\alpha=0.15$

Table 3 Baseline neonatal characteristics

\begin{tabular}{llll}
\hline & $\begin{array}{l}0 \% \text { Glucose acetated Ringer's } \\
\text { solution Group I }(n=15)\end{array}$ & $\begin{array}{l}1 \% \text { Glucose acetated Ringer's } \\
\text { solution Group II }(n=15)\end{array}$ & $\begin{array}{l}5 \% \text { Glucose acetated Ringer's } \\
\text { solution Group III }(n=15)\end{array}$ \\
\hline $\begin{array}{l}\text { Neonatal body } \\
\text { weight }(\mathrm{g})^{\mathrm{a}}\end{array}$ & $2668.0 \pm 460.3$ & $2685 \pm 593.1$ & $2570.0 \pm 566.6$ \\
$\begin{array}{l}\text { Apgar score } \\
1 \text { min }^{\mathrm{b}}\end{array}$ & $9(8-9)$ & $9(7-9)$ & $9(8-9)$ \\
$\begin{array}{l}\text { Apgar score } \\
5 \text { min }^{\mathrm{b}}\end{array}$ & $10(9-10)$ & $10(9-10)$ & $10(9-10)$ \\
Fetal pH & $7.428(7.389-7.466)$ & $7.391(7.310-7.452)$ & 0.53 \\
\hline
\end{tabular}

One-way ANOVA, $\alpha=0.15$

${ }^{\text {a }}$ Mean $\pm \mathrm{SD}$

${ }^{\mathrm{b}}$ Mean (minimun-maximum)

Table 4 Blood glucose levels of mothers

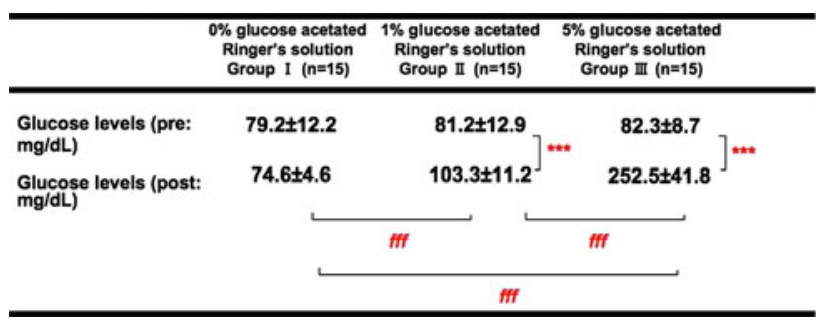

One-way ANOVA, $\alpha=0.05$

Mean \pm SD

*** $P<0.001$ for pre-infusion versus post-infusion

fff $P<0.001$ for each groups

pressure, a vasopressor is generally administered, and rapid infusion of an intravenous solution is often concomitantly used to have a faster effect. Currently, several solutions with different glucose concentrations are available for cesarean delivery, but are characterized by no uniformity.

Glucose passes between the mother and fetus through the placenta by diffusion, but its correlation coefficient is high, and there is no limit to the amount of glucose that can
Table 5 Blood glucose levels of fetuses and neonates

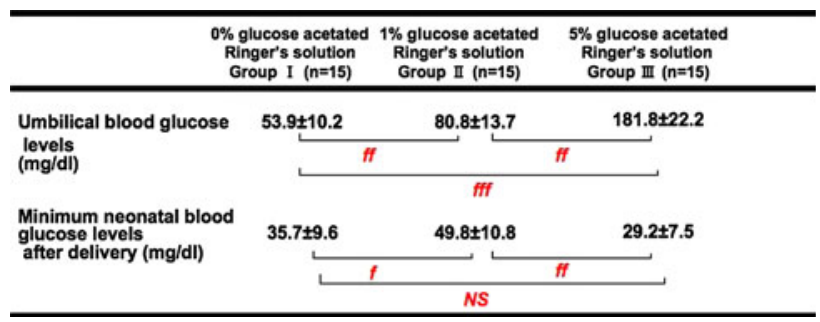

One-way ANOVA, $\alpha=0.05$

Mean \pm SD

$N S$ not significant

f $P<0.05$ for each groups

ff $P<0.01$ for each groups

fff $P<0.001$ for each groups

be passed [4]. Normally, the difference in blood glucose levels between the mother and fetus is within $20 \mathrm{mg} / \mathrm{dL}$, but if the mother receives a rapid glucose-containing infusion, the umbilical glucose levels have been reported to increase to $300 \mathrm{mg} / \mathrm{dL}$ or more [5]. 
Table 6 Number of neonates who received treatment

Chi-squared test, $\alpha=0.05$

\begin{tabular}{lllll}
\hline & $\begin{array}{l}0 \% \text { Glucose } \\
\text { acetated Ringer's } \\
\text { solution Group I } \\
(n=15)\end{array}$ & $\begin{array}{l}\text { 1\% Glucose acetated } \\
\text { Ringer's solution } \\
\text { Group II }(n=15)\end{array}$ & $\begin{array}{l}5 \% \text { Glucose acetated } \\
\text { Ringer's solution } \\
\text { Group III }(n=15)\end{array}$ & $P$ \\
\hline $\begin{array}{l}\text { No. of neonates who } \\
\text { received glucose } \\
\text { infusion therapy after } \\
\text { delivery }\end{array}$ & 6 & 3 & 9 & 0.082 \\
\hline
\end{tabular}

The use of glucose infusion in cesarean delivery has not been established.

Carbohydrate metabolism plays a central role in fetal metabolism. In 1959, Dawes and others [5] described the positive correlation between the period that a fetus can survive with anoxia and the amount of glycogen that accumulates in the heart [6]. During delivery, energy is derived from glucose via the Emden-Meyerhof pathway. When the mother-fetal condition is normal, increased fetal blood glucose is not as problematic as in instances of fetal distress, when providing glucose has been reported to benefit the fetus [7, 8]. If the fetus is stressed, catecholamines secreted from the adrenal gland and nerve endings enhance key enzymes of the Emden-Meyerhof pathway, degrade glycogen, and increase the blood glucose level. Furthermore, glucose load from intravenous solutions results in fetal hyperglycemia, and the excess glucose is not metabolized in the Krebs cycle, which may increase blood lactic acid and ultimately lead to lactic acidosis [1]. Especially rapid and large-dose administration should be contraindicated in cesarean delivery because it can result in maternal and fetal hyperglycemia, which may eventually lead to reflex hypoglycemia in the neonate [9-11].

In Japan, hypoglycemia in infants is generally defined as a blood glucose level of $30 \mathrm{mg} / \mathrm{dL}(1.7 \mathrm{mmol} / \mathrm{L})$ or lower. However, as mentioned above, at our institution, for safety, the definition of hypoglycemia in neonates is a minimum blood glucose level of $50 \mathrm{mg} / \mathrm{dL}(2.8 \mathrm{mmol} / \mathrm{L})$ or lower within $24 \mathrm{~h}$ after delivery [2]. Deshpande and colleagues [3] have reported that a blood glucose level of $48 \mathrm{mg} / \mathrm{dL}$ $(2.6 \mathrm{mmol} / \mathrm{L})$ or lower in neonates may lead to developmental disorders. Another study recommends that neonates with any abnormal clinical signs should be treated to have a blood glucose level of $45 \mathrm{mg} / \mathrm{dL}$ ( $2.5 \mathrm{mmol} / \mathrm{L})$ or higher [12].

As for blood glucose levels of the neonate after birth, Marom and colleagues showed that neonates had a level of $70.9 \pm 9.7 \mathrm{mg} / \mathrm{dL}$ when preoperative fasting lasted at least $6 \mathrm{~h}$ for mothers scheduled to have a cesarean delivery [13]. On the other hand, hypoglycemia may occur because pregnant women who are scheduled for elective cesarean delivery are required to fast after 21:00 the night before surgery. If the neonate's minimum blood glucose level is $50 \mathrm{mg} / \mathrm{dL}$ or lower within $8 \mathrm{~h}$ of birth, parenteral nutrition with a glucose-containing solution is begun to ensure the neonate's safety. In our study, neonates in Groups I and III were more likely to receive therapy than neonates in Group II. As a result, blood glucose levels in neonates in those 2 groups were significantly higher (Table 3 ). Group I mothers had hypoglycemia (no glucose load), which led to hypoglycemia in the neonate. In contrast, neonates in Group III had hyperglycemia immediately after birth. The glucose load in Group III mothers led to hyperglycemia and, subsequently, hyperinsulinemia in the fetus. In terminal gestation, mean immunoreactive plasma insulin (IRI) is $5 \mu \mathrm{U} / \mathrm{mL}$, which increases along with the elevation in fetal blood glucose levels due to maternal glucose load and fetal stress: there is a positive correlation between fetal blood glucose and fetal plasma insulin [14-16]. When the umbilical cord is clamped at delivery, however, glucose supply is terminated abruptly, leading to severe hypoglycemia due to hyperinsulinemia.

As a limitation of our study, we did not measure maternal, fetal, or neonatal insulin levels directly, which needs to be further investigated in future studies. In our hospital, glucose infusion is given as a prevention of neonatal hypoglycemia, but clinically speaking, first milk feeding may be started earlier. Also, this study was conducted as an exploratory study, and the sample size was not calculated, which might have led to the inconclusive results regarding glucose infusion in neonates with no statistical difference due to lack of statistical power. Further clinical studies with appropriate sample sizes may be conducted in the future.

The true purpose of our study is to further investigate how patients with gestational diabetes or pregestational diabetes respond to intravenous glucose solution. As a next step, we are planning to conduct a study with patients with pregestational diabetes.

In conclusion, our study results suggest that administration of $1 \%$ glucose acetated Ringer's solution $(500 \mathrm{~mL})$ during cesarean delivery is a reasonable treatment to maintain appropriate glucose levels in neonates.

Open Access This article is distributed under the terms of the Creative Commons Attribution License which permits any use, distribution, and reproduction in any medium, provided the original author(s) and the source are credited. 


\section{References}

1. Kenepp NB, Kumar S, Shelly WC, Stanley CA, Gabbe SG, Gutsche BB. Fetal and neonatal hazards of maternal hydration with $5 \%$ dextrose before caesarean section. Lancet. 1982;1:1150-2.

2. Heck LJ, Erenberg A. Serum glucose levels in term neonates during the first 48 hours of life. J Pediatr. 1987;110:119-22.

3. Deshpande S, Ward Platt M. The investigation and management of neonatal hypoglycaemia. Semin Fetal Neonatal Med. 2005;10: 351-61.

4. Bozzetti P, Ferrari MF, Marconi AM, Ferrazzi E, Pardi G, Makowski EL, Battaglia FC. The relationship of maternal and fetal glucose concentrations in the human from midgestation until term. Metabolism. 1988;37:358-63.

5. Oakley NW, Beard RW, Turner RC. Effect of sustained maternal hyperglycemia in normal and diabetic pregnancies. Br Med $\mathrm{J}$. 1972;1:466-9.

6. Dawes GS, Mott JC, Shelley HJ. The importance of cardiac glycogen for maintenance of life in foetal lambs and new-born animals during anoxia. J Physiol. 1959;146(3):516-38.

7. Benhamou D, Auroy Y. Fluid balance during labour: a French view. Int J Obstet Anesth. 1993;2:143-6.

8. Tan KH, Sabapathy A. Maternal glucose administration for facilitating tests of fetal wellbeing. Cochrane Database Syst Rev. 2001;(4):CD003397.
9. Bassett JM, Madill D. Influence of prolonged glucose infusions on plasma insulin and growth hormone concentrations of foetal lambs. J Endocrinol. 1974;62:299-309.

10. Soler NG, Malins JM. Diabetic pregnancy: management of diabetes on the day of delivery. Diabetologica. 1978;15:441-6.

11. Light IJ, Keenan WJ, Sutherland JM. Maternal intravenous glucose administration as a cause of hypoglycemia in the infant of the diabetic mother. Am J Obstet Gynecol. 1972;113:345-50.

12. Cornblath M, Hawdon JM, Williams AF, Aynsley-Green A, Ward-Platt MP, Shwartz R, Kalhan SC. Controversies regarding definition of neonatal hypoglycemia: suggested operational thresholds. Pediatrics. 2000;105(5):1141-5.

13. Marom R, Dollberg S, Mimouni FB, Berger I, Mordechayev N, Ochshorn Y, Mandel D. Neonatal blood glucose concentrations in caesarean and vaginally delivered term infants. Acta Paediatr. 2010;99(10):1474-7.

14. Obenshain SS, Adam PA, King KC, Teramo K, Raivio KO, Räihä N, Schwartz R. Human fetal insulin response to sustained maternal hyperglycemia. New Engl J Med. 1970;283:566-70.

15. Mendiola J, Grylack LJ, Scanlon JW. Effects of intrapartum maternal glucose infusion on the normal fetus and newborn. Anesth Analg. 1982;61:32-5.

16. Gylack LJ, Chu SS, Scanlon JW. Use of intravenous fluids before cesarean section: effects on perinatal glucose, insulin, and sodium homeostatsis. Obstet Gynecol. 1984;63:654-8. 